\title{
Electrically and Frequency-Tunable Printed Inverted-F Antenna with a Perturbed Parasitic Element
}

\author{
Yoon-Seon Choi ' Ji-Hun Hong · Jong-Myung Woo”
}

\begin{abstract}
This study designed an electrically and frequency-tunable printed inverted-F antenna (PIFA) with a perturbed parasitic element between the antenna and the ground plane. The resonant frequency of the proposed antenna can be changed via the short- and open-circuit operation of the parasitic element. This operation is activated using an electrical switch, which in this case is a PIN diode with an inductor and a resistor. The antenna was designed on the basis of the principles of the perturbation method, which enables control over resonant frequencies through modifications to the volume of a metal cavity. Meandered gaps were incorporated into the parasitic element for the independent operation of each PIN diode switch. The size of the PIFA's radiator is $4.8 \times 10 \mathrm{~mm}^{2}$, and the tunable resonant frequency at the $-10 \mathrm{~dB}$ bandwidth is $340 \mathrm{MHz}(17.3 \%)$.
\end{abstract}

Key Words: Printed Inverted-F Antenna, Perturbation Theory, Parasitic Elements, Frequency-Tunable Antenna.

\section{INTRODUCTION}

Recent developments in mobile communication technology gave rise to a bandwidth requirement of $300 \mathrm{MHz}(11.7 \%)$ for the $3.5 \mathrm{GHz}$ frequency band used for $5 \mathrm{G}$ technology. To meet this requirement, developers created many multiple-input, multiple-output antennas, which are mainly used in mobile communication $[1,2]$. These antennas, however, need additional space for multiple ports, making it difficult to satisfy the required bandwidth with a single antenna port in a given space. This problem was overcome through the development of frequency-tunable antennas. A variant of these innovations is the two-dimensional printed inverted-F antenna (PIFA), which is widely used in electronic devices as a communication antenna [3]. It can be easily fabricated through modern printing technology and fitted into a limited space because of its low-profile structure. Another example is the frequency-tunable planar inverted-F antenna equipped with a capacitor [4-7] (see also [8]). The capacitor is located between the main radiator and a parasitic element to vary resonant frequencies, after which capacitance is modified. This design means that the space occupied by a complex feeding structure expands because the antenna is directly connected to the radiator and parasitic element. An important consideration, however, is that using different capacitance values can contribute to antenna losses.

Previously developed frequency-reconfigurable antennas are equipped with yttrium-iron-garnet elements, and their resonant frequencies are tuned by changing the magnetic field, which is controlled by a DC bias [9]. The drawback to this design is that it reduces an antenna's radiation efficiency and increases fabrication costs.

In the present study, a frequency-tunable PIFA (FTPIFA)

Manuscript received June 25, 2019 ; Revised August 5, 2019 ; Accepted March 5, 2020. (ID No. 20190625-084J)

Department of Radio and Information Communication Engineering, Chungnam National University, Daejeon, Korea.

"Corresponding Author: Jong-Myung Woo (e-mail: jmwoo@cnu.ac.kr)

This is an Open-Access article distributed under the terms of the Creative Commons Attribution Non-Commercial License (http://creativecommons.org/licenses/by-nc/4.0) which permits unrestricted non-commercial use, distribution, and reproduction in any medium, provided the original work is properly cited.

(c) Copyright The Korean Institute of Electromagnetic Engineering and Science. All Rights Reserved. 
comprising a perturbed parasitic element was designed, with mobile devices as reference. The size of the antenna was reduced on the basis of perturbation theory [10-12] to the radiation element. The resonant frequency of the PIFA can be tuned by changing the volume of the electric and magnetic fields.

\section{ANTENNA DESIGN}

Fig. 1(a) and (b) show the designed PIFA with a parasitic element between the radiator and the ground plane. It was printed on a $0.8-\mathrm{mm}$ thick, $50 \times 100 \mathrm{~mm}^{2} \mathrm{FR}-4\left(\varepsilon_{r}=4.3, \tan \delta=\right.$ $0.025)$ substrate. The size of the antenna's radiator is $24.8 \times 10$ $\mathrm{mm}^{2}$. Because the position where a short circuit occurs ("short position" hereafter) can be tuned from switches \#1 to \#5 by using a copper strip, the central frequency $(2,045 \mathrm{MHz})$ is based on the shorted state of switch \#3.

Fig. 1(c) illustrates the new antenna structure used to change the short-circuit structure of the copper strip (Fig. 1(b)). A PIN diode (SMP1345-079LF) located between the parasitic element and the ground plane functions as a switch. It was redesigned by adding meandered gaps to the parasitic element for DC blocking and the independent operation of each switch.

The principles used to design the antenna are those underlying the perturbation method [11], through which resonant frequency can be controlled by changing the volume of a metal cavity (Fig. 2 and Eq. (1)). This method is also commonly used as reference in miniaturizing antennas.

$$
\frac{\omega-\omega_{o}}{\omega_{o}} \approx \frac{\iint_{\Delta \tau}\left(\mu\left|\overrightarrow{H_{o}}\right|^{2}-\varepsilon\left|\overrightarrow{o_{o}}\right|^{2}\right) d \tau}{\iiint_{\tau}\left(\mu\left|\overrightarrow{H_{o}}\right|^{2}+\varepsilon\left|\overrightarrow{E_{o}}\right|^{2}\right) d \tau}
$$

where $\omega_{o}$ is resonant frequency; $E_{o}$, electric field; and $H_{o}$, magnetic field.

Fig. 3 presents the fabricated prototype antenna.

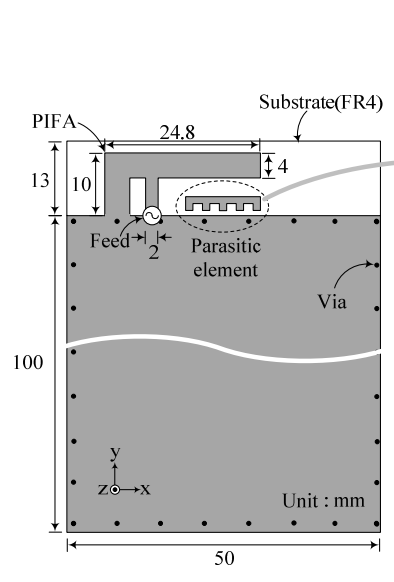

(a)

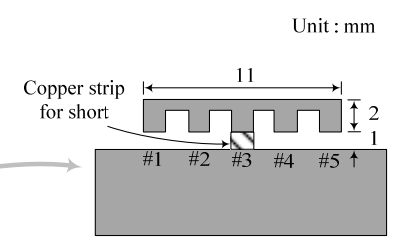

(b)

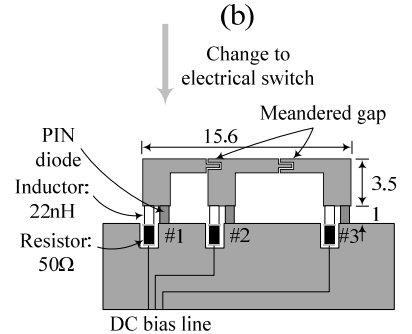

(c)
Fig. 1. (a) FTPIFA with basic perturbed parasitic element, (b) perturbed parasitic element, and (c) perturbed parasitic element with PIN diode switch.

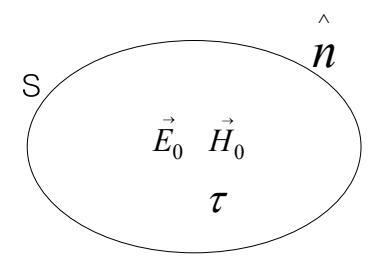

(a)

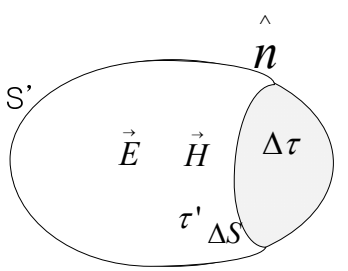

(b)
Fig. 2. Perturbation principle: (a) original metal cavity and (b) perturbed metal cavity.

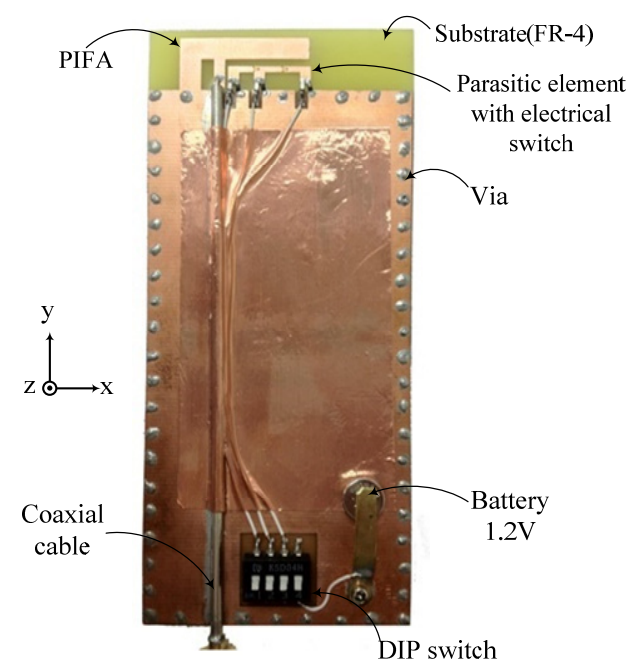

Fig. 3. Fabricated prototype antenna.

\section{SiMULATION AND MEASURED RESULTS}

Fig. 4 shows the FTPIFA's $S_{11}$, which was measured from the short-circuit operation of short positions \#1 to \#5 to verify changes in the resonant frequency of the antenna. Also Fig. 4 indicates that the resonant frequency decreased as the short position moved from \#1 to \#5 and that the central frequency (2.1 $\mathrm{GHz}$ ) was determined when switch \#3 was shorted. Because of the extent of the electric field, the magnetic energy between the antenna and the ground plane was changed by the short-circuit operation and on the basis of the perturbation principle [3]. In other words, the resonant frequency increased because of the

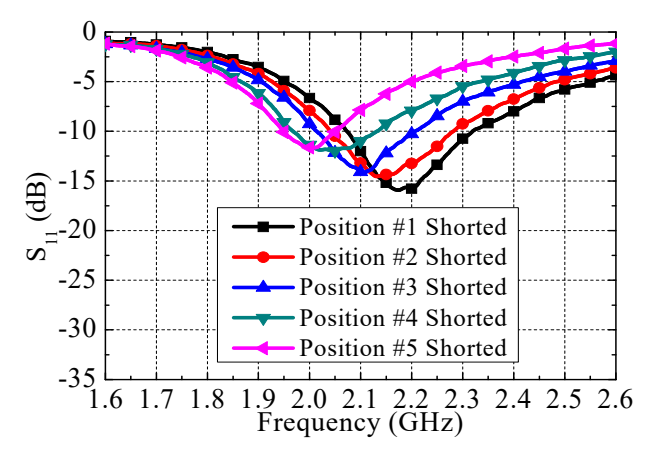

Fig. 4. Short position-based $S_{11}$ of the FTPIFA with a perturbed parasitic element. 


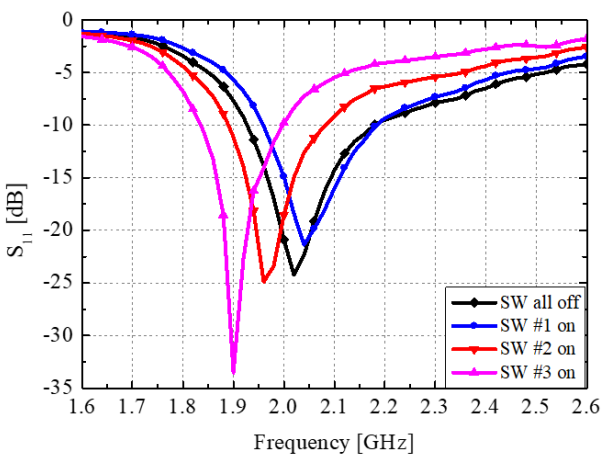

Fig. 5. Electrical switched-measured $S_{11}$ of the FTPIFA.

reduction in the volume of the magnetic field energy near the feeding point when position \#1 was shorted. Conversely, the resonant frequency decreased because of the reduction in the volume of the electric field energy at the edge of the radiated element when position \#5 was shorted.

The electrical operation of the shorted position was realized by applying a DC bias to the PIN diodes. An inductor $(22 \mathrm{nH})$ for AC cut-off and a meandered gap on the parasitic element for the independent operation of a switch were also used. Fig. 5 shows the $S_{11}$ measured from the operation of switches \#1 to \#3, which were manipulated by turning a PIN diode on and off to determine changes in the antenna's resonant frequency. The number of switches was limited to three for equal intervals of frequency movement. When switch \#1 was on, the upper frequency was resonant, but when switch \#3 was on, the resonant frequency decreased given the change in the volume of the electric field energy. The measured $-10 \mathrm{~dB}$ bandwidth covers 1.83 to $2.17 \mathrm{GHz}$, and the total tunable resonant frequency is 340 $\mathrm{MHz}$ (17.3\%).

Fig. 6 shows the radiation patterns measured at each resonant frequency of the antenna prototype when the switches were on. The H-plane patterns of the vertical element that indicates directivity to the $\mathrm{x}$-axis are shown in Fig. 6(a), and the H-plane patterns of the horizontal element overcoming a null point are displayed in Fig. 6(b). As can be seen, the designed antenna could maintain the radiation patterns of a basic inverted- $\mathrm{F}$ antenna, regardless of switch position.

Fig. 7 shows the simulated and measured peak gains when each switch was on. The simulated and measured average realized gains were $3.0 \mathrm{dBi}$ and $3.1 \mathrm{dBi}$, respectively, pointing to a reasonably good agreement between the simulation and measurement.

Finally, Table 1 summarizes the measured total efficiency and peak gain of the designed antenna at resonant frequencies. These amounted to $88.0 \%$ and $3.44 \mathrm{dBi}$ at $2.02 \mathrm{GHz}$, respectively, when all the switches were off. When the switches were activated (switched on) sequentially, the measured total efficiency was $72.0 \%$ for switch \#1, 68.9\% for switch \#2, and 56.2\% for switch \#3.

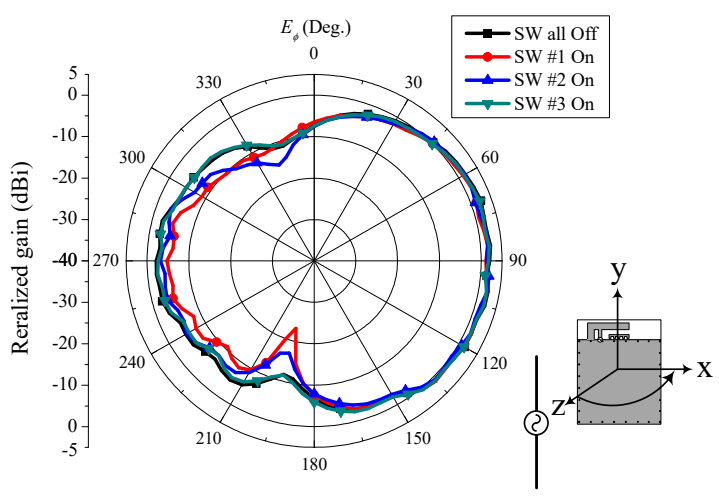

(a)

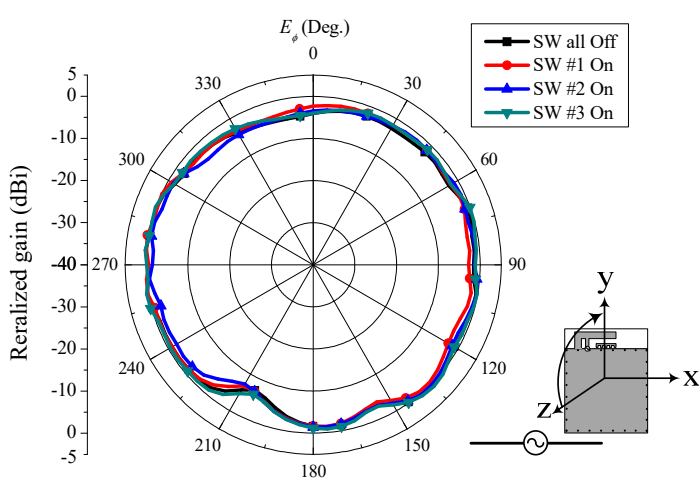

(b)

Fig. 6. Radiation patterns measured on the basis of short positions: (a) xz-plane $\left(\mathrm{E}_{\varphi}\right)$ and $(\mathrm{b}) \mathrm{yz}$-plane $\left(\mathrm{E}_{\varphi}\right)$.

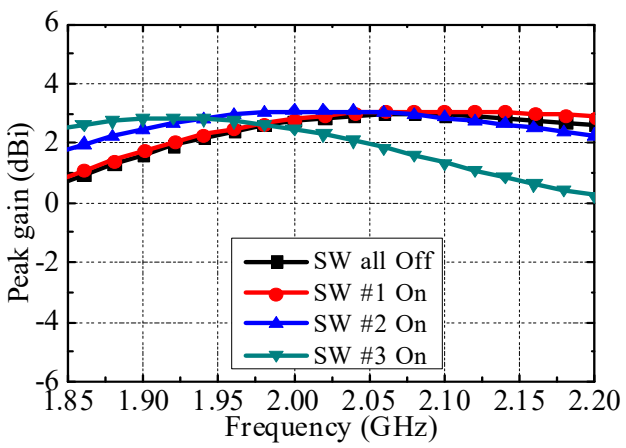

(a)

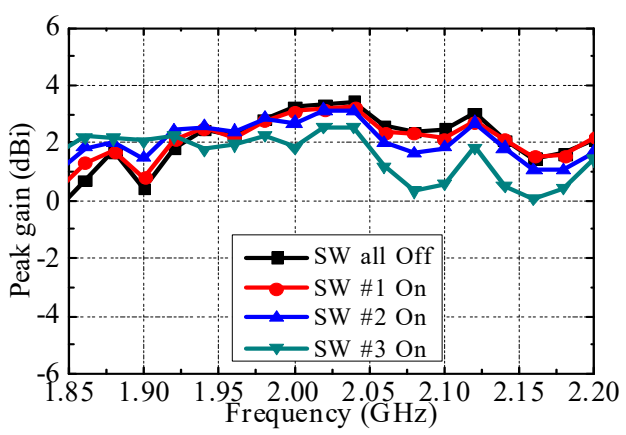

(b)

Fig. 7. Peak gains measured using an electrical switch: (a) simulation and (b) measurement. 
Table 1. Total efficiency levels and peak gains of the designed antenna

\begin{tabular}{lccc}
\hline & $\begin{array}{c}\text { Resonant } \\
\text { frequency } \\
(\mathrm{GHz})\end{array}$ & $\begin{array}{c}\text { Total } \\
\text { efficiency } \\
(\%)\end{array}$ & $\begin{array}{c}\text { Peak } \\
\text { gain } \\
(\mathrm{dBi})\end{array}$ \\
\hline All switches off & 2.02 & 88.0 & 3.22 \\
Switch \#1 on & 2.04 & 72.0 & 2.20 \\
Switch \#2 on & 1.96 & 68.9 & 2.17 \\
Switch \#3 on & 1.90 & 56.2 & 1.47 \\
\hline
\end{tabular}

\section{CONCLUSION}

An FTPIFA with a perturbed parasitic element was developed in this study. The designed antenna could be easily modified via the short- and open-circuit operation of the parasitic element between the antenna and the ground plane. It was redesigned by incorporating a gap capacitor into the parasitic element for the independent operation of each switch. As the resonant frequency varied considerably at the end of the radiator, a non-linear interval was arranged in the parasitic element. The antenna could also maintain the radiation patterns of a basic inverted-F antenna, regardless of switch position, and could be easily changed without loading and tuning the chip element on the antenna. Therefore, it is fully applicable to 5G technology and can selectively achieve the frequency band necessitated by an allocated frequency bandwidth.

\section{REFERENCES}

[1] L. Zhu, H. S. Hwang, E. Ren, and G. Yang, "High performance MIMO antenna for 5G wearable devices," in Proceedings of 2017 IEEE International Symposium on Antennas and Propagation \& USNC/URSI National Radio Science Meeting, San Diego, CA, 2017, pp. 1869-1870.

[2] M. Abdullah, Y. L. Ban, K. Kang, M. Y. Li, and M. Amin, "Compact four-port MIMO antenna system at $3.5 \mathrm{GHz}$," in Proceedings of 2017 IEEE 2nd Advanced Information Tech- nology, Electronic and Automation Control Conference (IAEAC), Chongqing, China, 2017, pp. 656-660.

[3] H. S. Lee, J. M. Woo, and J. C. Kim, "Printed type invertedF antenna," in Proceedings of 1999 KEES Microwave and Electromagnetic Wave Communication Conference, Gwangju, Korea, 1999, pp. 253-256.

[4] J. H. Lim, C. W. Song, Z. J. Jin, and T. Y. Yun, "Frequency reconfigurable planar inverted-F antenna using switchable radiator and capacitive load," IET Microwaves, Antennas \& Propagation, vol. 7, no. 6, pp. 430-435, 2013.

[5] V. A. Nguyen, M. T. Dao, Y. T. Lim, and S. O. Park, "A compact tunable internal antenna for personal communication handsets," IEEE Antennas and Wireless Propagation Letters, vol. 7, pp. 569-572, 2008.

[6] L. Liu, J. Rigelsford, and R. Langley, "Tunable multiband handset antenna operating at VHF and UHF bands," IEEE Transactions on Antennas and Propagation, vol. 61, no. 7, pp. 3790-3796, 2013.

[7] C. A. Balanis, Antenna Theory: Analysis and Design, 3rd ed. Hoboken, NJ: John Wiley \& Sons, 2005, pp. 197-204.

[8] J. T. Aberle, S. H. Oh, D. T. Auckland, and S. D. Rogers, "Reconfigurable antennas for wireless devices," EEE Antennas and Propagation Magazine, vol. 45, no. 6, pp. 148-154, 2003.

[9] D. M. Pozar and V. Sanchez, "Magnetic tuning of a microstrip antenna on a ferrite substrate," Electronics Letters, vol. 24, no. 12, pp. 729-731, 1988.

[10] R. F. Harrington. Time-Harmonic Electromagnetic Fields. New York, NY: McGraw-Hill, 1961, pp. 317-319.

[11] M. H. Song and J. M. Woo, "Miniaturisation of microstrip patch antenna using perturbation of radiating slot," Electronics Letters, vol. 39, no. 5, pp. 417-419, 2003.

[12] Y. R. Kim and J. M. Woo, "Electrically tunable small microstrip antenna using interdigital plate loading for telemetry sensor applications," Electronics Letters, vol. 48, no. 8, pp. 422-423, 2012. 


\section{Yoon-Seon Choi}

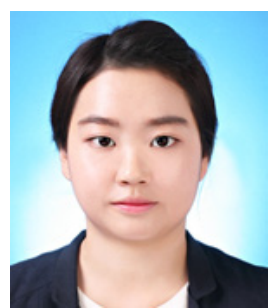

received her B.S. and M.S. degrees in radiowave engineering from Chungnam National University in 2014 and 2016, respectively. She is currently working toward her $\mathrm{Ph} . \mathrm{D}$. degree at the antenna laboratory. Her main research interest is antennas.

\section{Ji-Hun Hong}

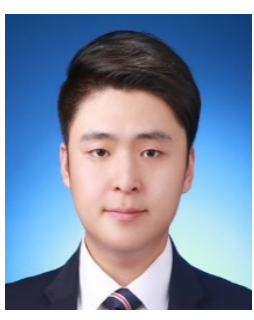

received his B.S. degree in radiowave engineering from Chungnam National University in 2018. He is $\mathrm{Cu}^{-}$ rrently working toward his M.S. degree at the antenna laboratory. His main research interest is antennas.

\section{Jong-Myung Woo}

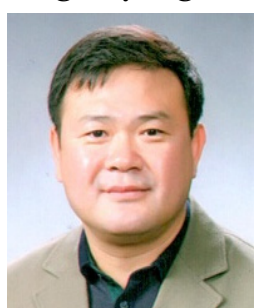

received his B.Sc. degree in electronics engineering from Konkuk University in Korea and Ph.D. degree in electronics engineering from Nihon University in Japan. He is a professor of Department of Radio and Information Communications Engineering in Chungnam National University in Korea. He is mainly interested in antennas. 